\section{Commentary: Juxtaposition of the atrial appendages: Fatal attraction or benign coupling?}

\author{
Ibrahim Abdullah, MD
}

In this issue of the JTCVS Techniques, Dr Cleuziou and colleagues ${ }^{1}$ from Germany present an interesting discovery in the case of an 11-week old infant with a diagnosis of a perimembranous ventricular septal defect and failure to thrive. ${ }^{1}$ During the operation, they incidentally recognize right juxtaposition of the morphologic left atrial appendage. In their case, the patient had an uneventful ventricular septal defect closure and was discharged 7 days later. However, they make a compelling case for knowing this anatomic finding in advance of the operation. Despite this, 2 questions arise: how easily can this diagnosis be made through routine echocardiography and whether juxtaposition of the atrial appendages carries any clinical significance.

One of the earliest descriptions of the echocardiographic techniques used to identify juxtaposition of the atrial appendages was published in 1983 by Rice and colleagues from the Mayo Clinic. ${ }^{2}$ They identified the combination of the parasternal short-axis plane at the level of the great arteries and the apical 4-chamber view as most helpful in elucidating juxtaposition of the atrial appendages. In 2010, Zhang and colleagues ${ }^{3}$ from the Shanghai Children's Medical Center retrospectively analyzed the echocardiographic findings of 10,880 patients with congenital heart disease who also underwent a cardiac catheterization. ${ }^{3}$ Of these, 33 patients were identified as having juxtaposition of the right atrial appendage by angiography and none had juxtaposition of the left atrial appendage. Of the 33 , only 28 were identified on echocardiogram. This underscores an important $15 \%$

From the Department of Pediatric Cardiac Surgery, King Faisal Specialist Hospital \& Research Center, Riyadh, Saudi Arabia.

Disclosures: The author reported no conflicts of interest.

The Journal policy requires editors and reviewers to disclose conflicts of interest and to decline handling or reviewing manuscripts for which they may have a conflict of interest. The editors and reviewers of this article have no conflicts of interest.

Received for publication April 12, 2021; revisions received April 12, 2021; accepted for publication April 12, 2021; available ahead of print April 16, 2021

Address for reprints: Ibrahim Abdullah, MD, Department of Pediatric Cardiac Surgery, King Faisal Specialist Hospital \& Research Center, Riyadh, Saudi Arabia (E-mail: iabdullah1234@gmail.com).

JTCVS Techniques 2021;7:236-7

2666-2507

Copyright (C) 2021 The Author(s). Published by Elsevier Inc. on behalf of The American Association for Thoracic Surgery. This is an open access article under the CC BY-NC-ND license (http://creativecommons.org/licenses/by-nc-nd/4.0/).

https://doi.org/10.1016/j.xjtc.2021.04.013

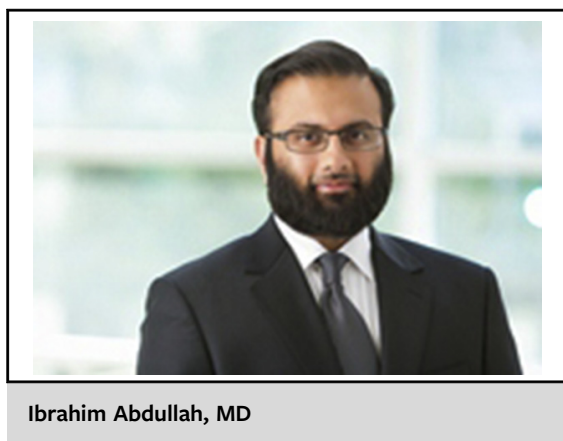

CENTRAL MESSAGE

Juxtaposition of the atrial appendages may portend higher risk, especially in single ventricle palliation.

nondetection rate by echocardiography even in this relatively recent series. Despite this, the clinical significance remains unclear.

The authors of this case report note a high correlation of complex congenital heart disease when juxtaposition of the atrial appendages is found. Limited published reports also tend to support that claim. For example, in an autopsy series of 1526 specimens from Padua, Italy, 17 cases of juxtaposition of the atrial appendages were discovered, including 9 with transposition of the great arteries, 6 with tricuspid atresia, and 1 with mitral atresia, while the other had aortic atresia. ${ }^{4}$ In an analysis of 18 postmortem cases of right juxtaposition of the left atrial appendage from the Boston Children's Hospital cardiac registry, $69 \%$ had mitral or tricuspid stenosis or atresia, $67 \%$ had left ventricular hypoplasia, and $39 \%$ had aortic outflow tract obstruction. With nearly two-thirds of this cohort having a single ventricle diagnosis, the surgical implications are significant. In another series that looked at surgical outcomes, Lai and colleagues ${ }^{6}$ found that 22 out of 7996 patients had juxtaposition of the atrial appendages. Of these, 11 underwent single ventricle palliation, with a $55 \%$ mortality rate. However, as with the patient in this case report, there was no mortality in the 8 who underwent biventricular repair. Could this have been an era effect of the mid- to late1990 s, or is there added inherent risk for single ventricle palliation when juxtaposition of the atrial appendages is found?

It remains to be seen what clinical significance juxtaposition of the atrial appendages truly carries, whether directly 
or as a marker of more advanced congenital heart disease, but the value of recording these findings remains clear.

\section{References}

1. Cleuziou J, Kemmer J, Sauer U, Pringsheim M. Juxtaposition of the atrial appendages in a patient with a simple ventricular septal defect. J Thorac Cardiovasc Surg Tech. 2021;7:233-5.

2. Rice MJ, Seward JB, Hagler DJ, Edwards WD, Julsrud PR, Tajik AJ. Left juxtaposed atrial appendages: diagnostic two-dimensional echocardiographic features. J Am Coll Cardiol. 1983;1:1330-6.
3. Zhang YQ, Yu ZQ, Zhong SW, Wu LP, Chen GZ, Zhang ZF, et al. Echocardiographic assessment of juxtaposition of the right atrial appendage in children with congenital heart disease. Echocardiography. 2010;27:878-84.

4. Frescura C, Thiene G. Juxtaposition of the atrial appendages. Cardiovasc Pathol. 2012;21:169-79.

5. Van Praagh S, O'Sullivan J, Brili S, Van Praagh R. Juxtapostion of the morphologically left atrial appendage in solitus and inversus atria: a study of 18 postmortem cases. Am Heart J. 1996;132(2 Pt 1):391-402.

6. Lai WW, Ravishankar C, Gross RP, Kamenir SA, Lopez L, Nguyen KH, et al Juxtaposition of the atrial appendages: a clinical series of 22 patients. Pediatr Cardiol. 2001;22:121-7. 